Lep. Rev. (1967) 38, 2, 87-92

\title{
Risk of Infection in Leprosy ${ }^{\star}$
}

\author{
N. FIGUEREDO \\ Special Officer, Acworth Leprosy Hospital, Wadala, Bombay 31 \\ Member, Leprosy Expert Group, Indian Council of Medical Research \\ V. BALKRISHNAN \\ Cancer Epidemiology Division, Indian Cancer Research Centre, Bombay \\ Part 1 \\ Treatment of Infector and Other Factors
}

This presentation consists of a statistical study of the risk of infection to contacts of infectious patients registered at the Clinic of the Acworth Leprosy Hospital, Bombay.

Involved in this study is, among other factors, the effect of treatment of the infectors on the risk of infection to their contacts.

Risk of infection has been defined as follows: Considering a group of contacts homogeneous for the factor or factors under consideration, the risk of infection is obtained as the quotient of the number of contacts who develop the disease to the total number of contacts. Thus it is the probability that a given contact from such a group will develop the disease.

\section{MATERIAL AND METHODS}

Information on 1,264 family members of patients who apparently commenced contact with their infectors before the age of $5 \frac{1}{2}$ years, and their infectors, were obtained from the Contact and Patient Register of the Acworth Leprosy Hospital, Bombay. Only Lepromatous, Infectious Borderline and Reactional Tuberculoid infectors were considered.

Items of information collected were:-

1. Sex of Contact.

2. Age at Start of Contact.

3. Duration of Contact.

4. Adequacy of Treatment of the Infectors.

Generally, the infectors and many of their infected contacts were registered at the hospital some time after the development of the disease.
The estimates of the duration of the disease given by the patients themselves are quite unreliable. Hence one of us (N.F.) scrutinized the case sheets of these patients and estimated the probable period between the development of the disease and registration at the hospital. Generally, the conservative estimates of 2 years for L1, 5 years for L2 and 8 years for L3 have been taken.

The estimated number of years of duration of the disease in the infectious state of the infector was subtracted from his or her year of registration to get the year in which he became infectious. Age at start of contact was the age of the contact in the above mentioned year and was obtained from the age of the contact in the year in which he was first examined. This factor is considered at 2 levels: $(a)$ at birth and (b) after birth.

Age at start of contact was subtracted from the age at last examination (in the case of noninfected contacts) and from the age at the time of becoming infected (in the case of infected contacts) to obtain the duration of contact. This factor is considered at 3 levels: $(a)$ short (1-4 years), (b) intermediate (5-8 years) and (c) long (more than 8 years).

For each infector, Sulphone treatment in months in each year from 1951 through 1962 was available. The period 1951 to 1962 was divided into 4 sub-periods of 3 years each.

* This study was undertaken with a grant given by W.H.O. 
Treatment for an average of 4 months per year in a sub-period was taken to be sufficient to assume adequate treatment for that sub-period from the start or from the date of registration if it fell within the sub-period. If a sub-period with adequate treatment on the above basis was followed by one or more sub-periods without adequate treatment, adequate treatment over all the sub-periods was assumed if and only if there was an average of 3 months of treatment per year over all the relevant sub-periods. Irrespective of the above criteria, if a patient became bacteriologically negative, he was assumed to have had adequate treatment for 2 years in case of L1, 4 years in case of L2 and 5 years in case of L3, prior to the date of becoming negative, or from the date of registration whichever was later.

The infector could be untreated or inadequately treated throughout the duration of contact; or, he could be adequately treated for the whole duration; or, he could be inadequately treated for some part of the duration and adequately treated for the remaining part. Treatment status of the infector is correspondingly considered at 3 levels: $(a)$ No or inadequate treatment (NT), $(b)$ Adequate treatment $(\mathrm{FT})$ and $(c)$ Mixed (PT).

Two hundred and eighteen out of 1,264 contacts had to be rejected for various reasons, such as lack of information on infector, presumed contact with non-infectious infectors, late age at start of contact, etc. This left 1,046 contacts who could be considered for analysis.

Most of the comparisons have been made using Chi Square. Interactions were studied using the arcsin transformation of the proportion infected. The effect of duration of contact on risk of infection may more appropriately be studied by the life table method. However, this would require the follow-up of a sufficient number of contacts for a long period (8 years or more) with observations at regular intervals (at least annually). Among the 1,046 contacts in the present study, only 105 had long duration of contact and even for these patients there were no observations at regular intervals. Even if a specific study were to be started with this aim, there would be enormous difficulties in follow-up, since the addresses given vary from 'foot path' and 'hut' to somewhat more permanent locations.

\section{RESULTS}

Out of 1,046 contacts, 291 or $27.8 \%$ were found to be infected. This high risk might be due to various reasons.

(a) Contacts were all young, about 70\% having contact at birth.

(b) Extreme poverty accentuating crowded living and low nutritional status.

Apart from these, selection of contacts through the Contact Register might have introduced an upward bias in that many of the contacts are

TABLE 1

Distribution of contacts with respect to various factors

\begin{tabular}{llcccc}
\hline \multicolumn{1}{c}{ Factor } & \multicolumn{1}{c}{ Levels } & Total & Not Infected & Infected & \% Infected \\
\hline Sex of & Male & 546 & 389 & 157 & 28.75 \\
Contact & Female & 500 & 366 & 134 & 26.80 \\
\hline Age at & At Birth & 716 & 536 & 180 & 25.14 \\
Start & After Birth & 330 & 219 & 111 & 33.64 \\
\hline Duration & Short & 559 & 372 & 187 & 33.45 \\
of & Intermediate & 382 & 295 & 87 & 22.77 \\
Contact & Long & 105 & 88 & 17 & 16.19 \\
\hline Treatment & FT & 114 & 97 & 17 & 14.91 \\
of & PT & 289 & 234 & 55 & 19.03 \\
Infector & NT & 643 & 424 & 219 & 34.06 \\
\hline & $\quad$ Total & 1,046 & 755 & 291 & 27.82 \\
\hline
\end{tabular}


brought to the hospital for examination only when they start showing signs of infection. Two hundred and fifty-six out of the 291 infected contacts were found to be infected at the first examination itself.

Table 1 gives the distribution of contacts according to $(a)$ Sex of Contact, $(b)$ Age at Start of Contact), (c) Duration of Contact, and (d) Treatment Status of Infector.

There is no difference in the risk of infection between the 2 sexes, the Chi Square value being 0.50 with 1 degree of freedom and probability great than 0.30 .

The risk of infection rises sharply for those contacts who start contact after birth. This rise is highly significant, the Chi Square value being 7.55 with 1 degree of freedom and probability less than 0.01 .

The risk of infection decreases with increasing duration of contact. This decrease is very highly significant, the Chi Square value being 20.74 with 2 degrees of freedom and probability less than 0.001 .

The risk of infection decreases with rising treatment status of infector. This decrease is very highly significant, the Chi Square value being 33.05 with 2 degrees of freedom and probability less than 0.001 .

Treatment status PT is a heterogenous group in that the proportion of the duration of contact lying within the treated period is highly variable. The way to overcome this difficulty is to partition this group into FT and NT according as the infector had been treated for more than half the duration of contact or not. The distribution of contacts according to this modified definition of treatment status is given in Table 2.

TABI,E 2

Distribution of contacts with respect to treatment status of infector (PT partitioned)

\begin{tabular}{lrcrc}
\hline $\begin{array}{c}\text { Treatment } \\
\text { Status }\end{array}$ & Total & $\begin{array}{c}\text { Not } \\
\text { Infected }\end{array}$ & Infected & $\begin{array}{c}\% \\
\text { Infected }\end{array}$ \\
\hline FT & 204 & 180 & 24 & 11.76 \\
NT & 842 & 575 & 267 & 31.71 \\
\hline Total & 1,046 & 755 & 291 & 27.81 \\
\hline
\end{tabular}

Risk of infection with an untreated infector is almost thrice that with a treated infector. The difference is very highly significant, the Chi Square value being 32.53 with 1 degree of freedom and probability less than 0.001 .

In summary, risk of infection rises sharply for those who start contact after birth while it decreases highly significantly with increasing duration of contact and rising treatment status of infector.

It is quite likely that more of the contacts starting contact at birth have also treated infectors. Similarly contacts with longer duration of contact may have a greater chance of having treated infectors. It will be of interest to see whether these interactions are the reasons for the above results.

The distribution of contacts according to age at start and duration of contact is given in Table 3 .

TABLE 3

Distribution of contacts according to age at start and duration of contact with $\%$ infected and arcsin transformation

\begin{tabular}{cccccc}
\hline \multirow{2}{*}{$\begin{array}{c}\text { Age at } \\
\text { Start of } \\
\text { Contact }\end{array}$} & & \multicolumn{4}{c}{ Duration of Contact } \\
\cline { 3 - 6 } & & Short & Intermediate & Long & Total \\
\hline \multirow{2}{*}{ At Birth } & Total & 423 & 223 & 70 & 716 \\
& \% I & 26.95 & 25.11 & 14.29 & 25.14 \\
& Arcsin & 31.27 & 30.07 & 22.21 & $(30.01)$ \\
\hline \multirow{2}{*}{ After } & Total & 136 & 159 & 35 & 330 \\
Birth & \% I & 53.68 & 19.50 & 20.00 & 33.64 \\
& Arcsin & 47.11 & 26.21 & 26.56 & $(34.86)$ \\
\hline Total & Total & 559 & 382 & 105 & 1,046 \\
& \% I & 33.45 & 22.77 & 16.19 & 27.82 \\
& Arcsin & $(35.12)$ & $(28.46)$ & $(23.66)$ & $(31.83)$ \\
\hline
\end{tabular}


Among those who commenced contact at birth, $60 \%$ have short duration, $30 \%$ have intermediate duration and $10 \%$ have long duration. Among the other contacts, 40\% have short duration, $50 \%$ have intermediate duration and $10 \%$ have long duration. Thus the smaller risk in those commencing contact at birth could not have been caused by a larger proportion of them having longer duration of contact.

Among contacts who had short, intermediate and long periods of contast, 75, 58 and $67 \%$ respectively commenced contact with the infector at birth. Thus the smaller risk with increasing duration of contact could not have been caused by a larger proportion of them being contacts starting contact at birth.

Analysis of variance of \% infected shows that each factor must be considered separately for different levels of other factors. For contacts starting at birth, short or intermediate duration does not make any difference. But long duration significantly decreases the risk, the Chi Square value being 4.23 with 1 degree of freedom and probability less than 0.05 .

For contacts starting contact after birth, intermediate or long duration does not make any difference. But short duration increases the risk very highly significantly. The Chi Square value being 40.11 with 1 degree of freedom and probability less than 0.001 .

For contacts having intermediate or long duration, whether the contact started at or

TABLE 4

Distribution of contacts according to age at start of contact and treatment status of infector, with $\%$ infected and arcsin transformation

\begin{tabular}{ccccc}
\hline \multirow{2}{*}{$\begin{array}{c}\text { Age } \\
\text { at } \\
\text { Start }\end{array}$} & & \multicolumn{3}{c}{ Treatment Status } \\
\cline { 3 - 5 } & & $F T$ & $N T$ & Total \\
\hline At Birth & Total & 190 & 526 & 716 \\
& \% I & 12.63 & 29.66 & 25.14 \\
& Arcsin & 20.82 & 33.00 & $(29.77)$ \\
\hline After & Total & 14 & 316 & 330 \\
Birth & \% I & 0.00 & 35.13 & 33.64 \\
& Arcsin & 0.00 & 36.35 & $(34.81)$ \\
\hline \multirow{2}{*}{ Total } & Total & 204 & 842 & 1,046 \\
& \% I & 11.76 & 31.71 & 27.82 \\
& Arcsin & $(19.39)$ & $(34.26)$ & $(31.36)$ \\
& & & &
\end{tabular}

after birth does not make any difference. But for contacts having short duration, start of contact after birth increases the risk very significantly, the Chi Square value being 31.83 with 1 degree of freedom and probability less than 0.001 .

The distribution of contacts according to age at start of contact and treatment status of infector is given in Table 4.

Amone contacts starting contact at birth, about $26 \%$ have treated infectors while among the other only $4 \%$ have treated infectors. Hence the reduced risk at birth might be due to the higher proportion of treated infectors for this group. Similarly among contacts having treated infectors only $7 \%$ start contact after birth while among contacts having untreated infectors this proportion is about $38 \%$.

Analysis of variance of \% infected is given in Table 5.

TABLE 5

Analysis of variance of data in Table 4

\begin{tabular}{lrrr}
\hline \multicolumn{1}{c}{ Source } & $d . f$. & \multicolumn{1}{c}{$s s$} & \multicolumn{1}{c}{$F$} \\
\hline Total & 3 & 44023.3844 & \\
Age at Start & 1 & 5741.7078 & 6.99 \\
Treatment Status & 1 & 36305.5060 & 44.22 \\
Interaction & 1 & 1976.1706 & 2.41
\end{tabular}

The interaction is not significant.

TABLE 6

Distribution of contacts according to duration of contact and treatment status of infector, with $\%$ infected and arcsin transformation

\begin{tabular}{llccc}
\hline \multirow{2}{*}{$\begin{array}{c}\text { Duration } \\
\text { of }\end{array}$} & & \multicolumn{3}{c}{ Treatment Status } \\
\cline { 3 - 5 } Contact & & $F T$ & $N T$ & Total \\
\hline Short & Total & 96 & 463 & 559 \\
& \% I & 12.50 & 37.80 & 33.45 \\
& Arcsin & 20.70 & 37.94 & $(34.98)$ \\
\hline Inter- & Total & 79 & 303 & 382 \\
mediate & \% I & 12.66 & 25.41 & 22.77 \\
& Arcsin & 20.84 & 30.27 & $(28.32)$ \\
\hline \multirow{2}{*}{ Long } & Total & 29 & 76 & 105 \\
& \% I & 6.90 & 19.74 & 16.19 \\
& Arcsin & 15.23 & 26.38 & $(23.3 \%)$ \\
\hline Total & Total & 204 & 842 & 1,046 \\
& \% I & 11.76 & 31.71 & 27.82 \\
& Arcsin & $(19.88)$ & $(34.14)$ & $(31.38)$ \\
& & & &
\end{tabular}


The distribution of contacts according to duration of contact and treatment status of infector is given in Table 6 .

Contacts with treated infectors increase from $17.2 \%$ among those with short duration to $20.7 \%$ among those with intermediate duration to $27.6 \%$ among those with long duration. Hence, the reduced risk with increasing duration might partly be due to the higher proportion of contacts with treated infectors. Among contacts with treated infectors, $47 \%$ are with short duration and $14 \%$ with long duration while among contacts with untreated infectors, $55 \%$ are with short duration and only $9 \%$ are with long duration.
Analysis of variance of $\%$ infected is given in Table 7.

TABLE 7

Analysis of variance of data in Table 6

\begin{tabular}{lcrr}
\hline \multicolumn{1}{c}{ Source } & $d . f$. & \multicolumn{1}{c}{$s s$} & $F$ \\
\hline Total & 5 & 51309.0424 & \\
Duration of Contract & 2 & 17676.6072 & 10.76 \\
Treatment Status & 1 & 32925.8592 & 40.10 \\
Interaction & 2 & 706.5760 & 0.43 \\
\hline
\end{tabular}

Interaction is not significant.

TABLE 8

Distribution of contacts according to age at start of contact, duration of contact and treatment status of infector

\begin{tabular}{|c|c|c|c|c|c|}
\hline \multirow{2}{*}{$\begin{array}{c}\text { Age } \\
\text { of } \\
\text { Start }\end{array}$} & \multirow{2}{*}{$\begin{array}{c}\text { Duration } \\
\text { of } \\
\text { Contact }\end{array}$} & & \multicolumn{3}{|c|}{ Treatment Status } \\
\hline & & & $F T$ & $N T$ & Total \\
\hline \multirow[t]{8}{*}{ At Birth } & Short & $\mathrm{T}$ & 93 & 330 & 423 \\
\hline & & $\% \mathrm{I}$ & 12.90 & 30.91 & 26.95 \\
\hline & Intermediate & $\mathrm{T}$ & 75 & 148 & 223 \\
\hline & & $\%$ I & 13.33 & 31.08 & 25.11 \\
\hline & I،ong & $\mathrm{T}$ & 22 & & 70 \\
\hline & & $\%$ I & 9.09 & 16.67 & 14.29 \\
\hline & Total & $\mathrm{T}$ & 190 & 526 & 716 \\
\hline & & $\%$ I & 12.63 & 29.66 & 25.14 \\
\hline \multirow[t]{8}{*}{ After Birth } & Short & $\mathrm{T}$ & 3 & 133 & 136 \\
\hline & & $\%$ I & 0.00 & 54.89 & 53.68 \\
\hline & Intermediate & $\mathrm{T}$ & 4 & 155 & 159 \\
\hline & & $\%$ I & 0.00 & 20.00 & 19.50 \\
\hline & Long & $\mathbf{T}$ & 7 & 28 & \\
\hline & & $\%$ I & 0.00 & 25.00 & 20.00 \\
\hline & Total & $\mathrm{T}$ & 14 & 316 & 330 \\
\hline & & $\%$ I & 0.00 & 35.13 & 33.64 \\
\hline \multirow[t]{8}{*}{ Total } & Short & $\mathrm{T}$ & 96 & 463 & 559 \\
\hline & & $\% \mathrm{I}$ & 12.50 & 37.80 & 33.45 \\
\hline & Intermediate & $\mathrm{T}$ & 79 & 303 & 382 \\
\hline & & $\%$ I & 12.66 & 25.41 & 22.77 \\
\hline & Long & $\mathrm{T}$ & 29 & 76 & 105 \\
\hline & & $\%$ I & 6.90 & 19.74 & 16.19 \\
\hline & Total & $\mathrm{T}$ & 204 & 842 & 1,046 \\
\hline & & $\%$ I & 11.76 & 31.71 & 27.82 \\
\hline
\end{tabular}




\section{DISCUSSION}

The foregoing analysis of the data has clearly shown that treatment of the infector helps to reduce the risk of infection to his contacts highly significantly; and this independently of the age at whish the contact started and the period of contact, as shown by the small values for interaction of treatment status with both, age at start of contart, and duration of contact.

Some other interesting results have also evolved from the analysis. Contrary to expectation, it was found that the longer the duration of contast, the less the risk of infection. Again, the risk is less if the contact starts at birth itself rather than later. These unexpected results besome meaningful when the interaction between the 2 factors, which is highly significant, is taken into consideration. The only significant difference in the risk between those starting contact at birth and after birth is for short duration. It might be that individuals starting contact at birth might have some amount of immunity at birth itself. This is further borne out by the fast that such contacts maintain the same risk for a longer duration while those who start contact after birth have a precipitate fall in risk from short to intermediate duration.

The distribution of contacts with risk of infection with respect to all the 3 factors is given in Table 8.

It will be seen that, for all groups of contacts, treatment of the infector reduces the risk of infection substantially.
If we consider a cohort of 1,000 contacts starting contact at birth (or in utero), 309 will get infected in 4 years, another 215 in the next 4 years, and another 79 subsequently. In all 603 or about $60 \%$ will be infected, if the infector is untreated. However, if the infector has adequate treatment, those infected reduce to 129,116 and 69 , or in all to 314 or about $31 \%$.

If contact started after birth, 549 will be infected in the first 4 years, 90 in the next 4 years, and another 90 subsequently, so that in all 729 , or about $73 \%$, will be infected if the infector is untreated. However, if the infector has adequate treatment, there is practically no risk.

\section{SUMMARY}

Data on 1,046 family members of patients who commenced contact with their infectors before $5 \frac{1}{2}$ years of age, was analysed to study the risk of infection. The effect of treatment of the infectors on the risk of infection to the contacts, was also studied.

The risk of infection was found to be reduced substantially when the infector reseived adequate treatment.

It was also found that when contact commenced after birth higher risk resulted but decreased with increasing duration of contact. These results have been explained as probably due to the built-in immunity of those contarts who started contact at birth. 


\section{Part 2}

\section{Chemoprophylaxis}

This presentation is a statistical analysis of the results of chemoprophylaxis with DDS, taking into account various factors which influence the risk of infection as shown in Part I of this paper.

\section{MATERIAL AND METHOD}

The factors considered in this study are:-

1. Sex of contact: Male, Female.

2. Age at start of contact:

Child (0-15 years).

Adult (above 15 years).

3. Duration of contact:

Short (1-4 years).

Intermediate (5-8 years).

Long (more than 8 years).

4. Treatment status of infector:

Fully Treated: FT.

Not Treated: NT.

5. Level of Prophylaxis:

Adequate: AP.

None: NP.

The methods for obtaining factor (2), (3) and (4) have been detailed in the earlier part. Treatment status has been considered only at 2 levels, with the partly treated group split into fully treated and not treated according to whether the infector has been getting adequate treatment for more than half the duration of contact or not.

Prophylaxis has been considered adequate if there was 3 years or more of prophylaxis with an average of 8 months per year and no long break within the first 3 years.

It may be noted that the infectors may vary in the virulence of their disease and that the contacts may vary in the period spent without prophylaxis. These factors have not been taken into account.

The statistical methods used are the Chi Square and the Analysis of Variance of the Arcsin transformation of $\%$ infected.

\section{RESULTS}

Out of 575 contacts with full information, 49 were found to be infected, giving a rate of infection of $8.52 \%$. This is only about one-third of the rate of $27.82 \%$ found in the earlier report on children. This reduced risk may be due to 2 factors: In the present study, (1) only about $55 \%$ of the contacts had a starting age below 5 years and the risk is very much reduced for adults (vide Table 2) and (2) all contacts who first came to the hospital in an infected stage are excluded.

Out of 51 contacts with adequate prophylaxis, none was found to be infected, while 49 out of 524 contacts with no prophylaxis were found to be infected, giving a rate of $9.35 \%$. The difference is significant, the Chi Square value being 5.23 with 1 degree of freedom.

Table 1 gives the distribution of the contacts according to levels of prophylaxis and sex of contact.

TABLE 1

Distribution of contacts according to levels of prophylaxis and sex of contact

\begin{tabular}{clcccr}
\hline Prophylaxis & Sex & Total & NI & $I$ & $\% I$ \\
\hline \multirow{2}{*}{ AP } & Male & 27 & 27 & - & 0.00 \\
& Female & 24 & 24 & - & 0.00 \\
\cline { 2 - 6 } & Total & 51 & 51 & - & 0.00 \\
\hline \multirow{2}{*}{ NP } & Male & 267 & 237 & 30 & 11.24 \\
& Female & 257 & 238 & 19 & 7.39 \\
\cline { 2 - 6 } & Total & 524 & 475 & 49 & 9.35 \\
\hline \multirow{2}{*}{ Total } & Male & 294 & 264 & 30 & 10.20 \\
& Female & 281 & 262 & 19 & 6.76 \\
\cline { 2 - 6 } & Total & 575 & 526 & 49 & 8.52 \\
\hline
\end{tabular}

Males and Females are about equally distributed in both prophylactic groups. The sex difference is not significant either among all patients $($ Chi Square=2.19, with 1 d.f.), or among those with no prophylaxis (Chi Square $=2.28$, with 1 d.f.). 
Table 2 gives the distribution of contacts according to levels of prophylaxis and age at start of contact.

TABLE 2

Distribution of contacts according to levels of prophylaxis and age at start

\begin{tabular}{|c|c|c|c|c|c|}
\hline \multicolumn{2}{|c|}{$\begin{array}{r}\text { Age at } \\
\text { Prophylaxis Start }\end{array}$} & \multirow{2}{*}{$\begin{array}{c}\text { Total } \\
38\end{array}$} & \multirow{2}{*}{$\begin{array}{c}N I \\
38\end{array}$} & \multirow{2}{*}{$\begin{array}{r}I \\
-\end{array}$} & \multirow{2}{*}{$\frac{0 \%}{0.00}$} \\
\hline $\mathrm{AP}$ & Child & & & & \\
\hline & Adult & 13 & 13 & - & 0.00 \\
\hline & Total & 51 & 51 & - & 0.00 \\
\hline \multirow[t]{3}{*}{ NP } & Child & 358 & 319 & 39 & 10.89 \\
\hline & Adult & 166 & 156 & 10 & 6.02 \\
\hline & Total & 524 & 475 & 49 & 9.35 \\
\hline \multirow[t]{3}{*}{ Total } & Child & 396 & 357 & 39 & 9.85 \\
\hline & Adult & 179 & 169 & 10 & 5.59 \\
\hline & Total & 575 & 526 & 49 & 8.52 \\
\hline
\end{tabular}

$74.5 \%$ of the contacts with adequate prophylaxis are contacts with an earlier starting age, while this percentage is only 68.32 for contacts with no prophylaxis. This difference is not significant (Chi Square $=0.83$, with 1 d.f.). Even if this was significant, this should tend to give a lower risk for the no prophylaxis group since early starters have a higher risk.

The effect of age at start of contact is to decrease the risk with increasing age at start, even though this effect is not found to be significant either among all cases (Chi Square = 2.87, with 1 d.f.) or among those with no prophylaxis (Chi Square $=3.17$, with 1 d.f.).

Table 3 gives the distribution of contacts according to levels of prophylaxis and duration of contact.

Most contacts spend a part of the duration of contact in the beginning with no prophylaxis. Also, adequate prophylaxis requires a minimum of 3 years of prophylaxis. These 2 factors together ensure that most of the contacts with adequate prophylaxis will also have long
TABLE 3

Distribution of contacts according to levels of prophylaxis and duration of contact

\begin{tabular}{|c|c|c|c|c|c|}
\hline Prophylaxis & $s$ Duration & Total & $N I$ & $I$ & $\% I$ \\
\hline \multirow[t]{4}{*}{$\mathrm{AP}$} & Short & 1 & 1 & - & 0.00 \\
\hline & $\begin{array}{l}\text { Inter- } \\
\text { mediate }\end{array}$ & 3 & 3 & - & 0.00 \\
\hline & Long & 47 & 47 & - & 0.00 \\
\hline & Total & 51 & 51 & - & 0.00 \\
\hline \multirow[t]{4}{*}{ NP } & Short & 103 & 88 & 15 & 14.56 \\
\hline & $\begin{array}{l}\text { Inter- } \\
\text { mediate }\end{array}$ & 250 & 227 & 23 & 9.20 \\
\hline & Long & 171 & 160 & 11 & 6.43 \\
\hline & Total & 524 & 475 & 49 & 9.35 \\
\hline \multirow[t]{4}{*}{ Total } & Short & 104 & 89 & 15 & 14.42 \\
\hline & $\begin{array}{l}\text { Inter- } \\
\text { mediate }\end{array}$ & 253 & 230 & 23 & 9.09 \\
\hline & Long & 218 & 207 & 11 & 5.05 \\
\hline & Total & 575 & 526 & 49 & 8.52 \\
\hline
\end{tabular}

duration. Since the risk of infection is found to decrease with increasing duration of contact, this could be one of the reasons for the reduced risk with adequate prophylaxis. Comparison of the contacts with long duration shows no significant differences between the adequate and no prophylaxis groups (Chi Square $=3.18$, with 1 d.f.). However, 53 of the 171 contacts with no prophylaxis and long duration had some prophylaxis and only one of them was found to be infected. Removing these, a rate of $8.47 \%$ is found for contacts with no prophylaxis at all and this is found to be significantly different from the rate for these with adequate prophylaxis (Chi Square $=4.24$, with 1 d.f..

As in the earlier study, the risk is found to decrease with increasing duration of contact. This decrease is significant among all patients (Chi Square $=8.14$, with 2 d.f.) but not so among those with no prophylaxis (Chi Square $=4.91$, with 2 d.f.).

Table 4 gives the distribution of contacts according to levels of prophylaxis and treatment status of infector.

\section{Leprosy Review}


TABLE 4

Distribution of contacts according to levels of prophylaxis and treatment status of infector

\begin{tabular}{llcccr}
\hline \multirow{4}{*}{ Prophylaxis } & $\begin{array}{c}\text { Treat- } \\
\text { ment } \\
\text { Status }\end{array}$ & Total & NI & $I$ & $\%$ I \\
\hline \multirow{2}{*}{ AP } & FT & 38 & 38 & - & 0.00 \\
& NT & 13 & 13 & - & 0.00 \\
\cline { 2 - 6 } & Total & 51 & 51 & - & 0.00 \\
\hline \multirow{2}{*}{ NP } & FT & 167 & 160 & 7 & 4.19 \\
& NT & 357 & 315 & 42 & 16.34 \\
\cline { 2 - 6 } & Total & 524 & 475 & 49 & 9.35 \\
\hline \multirow{2}{*}{ Total } & FT & 205 & 198 & 7 & 3.41 \\
& NT & 370 & 328 & 42 & 11.35 \\
\cline { 2 - 6 } & Total & 575 & 526 & 49 & 8.52
\end{tabular}

$74.5 \%$ of the contacts with adequate prophylaxis have also fully treated infectors while only $31.9 \%$ of the contacts with no prophylaxis have such infectors. This difference is found to be highly significant (Chi Square= 36.83 , with 1 d.f.). Since contacts with fully treated infectors have a smaller risk, this could be a reason for the apparent reduction in risk with adequate prophylaxis. In fact, prophylaxis is found to have no effect with fully treated infectors (Chi Square $=1.65$, with 1 d.f.) as well as with untreated infectors (Chi Square $=1.73$, with 1 d.f.).

Treatment of infector reduces the risk highly significantly among all contacts (Chi Square $=10.66$, with 1 d.f.) and among contacts with no prophylaxis (Chi Square $=7.70$, with 1 d.f.).

\section{DISCUSSION}

In summary, there is no significant difference in the rate of infection between the 2 sexes or between those who start contact as children or as adults (though the rate for the latter is only about half that for the former). The rate of infection decreases with increasing duration of contact and with treatment of infector. The 2 prophylactic groups do not differ in their distribution with respect to sex or age at start but do so highly significantly with respect to duration of contact and treatment status. Also these significant differences are in the direction which would tend to give a lower rate for those with adequate prophylaxis. In fact, prophylaxis does not appear to have any significant effect

TABLE 5

Distribution of Contacts in a restricted sample (duration more than 8 years)

\begin{tabular}{|c|c|c|c|c|c|c|}
\hline $\begin{array}{c}\text { Pro- } \\
\text { phylaxis }\end{array}$ & $\begin{array}{c}\text { Age at } \\
\text { Start }\end{array}$ & $\begin{array}{c}\text { Treat- } \\
\text { ment } \\
\text { Status }\end{array}$ & Total & $N I$ & $I$ & $\% I$ \\
\hline \multirow[t]{9}{*}{$\mathrm{AP}$} & \multirow[t]{3}{*}{ Child } & FT & 25 & 25 & - & 0.00 \\
\hline & & NT & 10 & 10 & - & 0.00 \\
\hline & & Total & 35 & 35 & - & 0.00 \\
\hline & \multirow[t]{3}{*}{ Adult } & FT & 10 & 10 & - & 0.00 \\
\hline & & NT & 2 & 2 & - & 0.00 \\
\hline & & Total & 12 & 12 & - & 0.00 \\
\hline & \multirow[t]{3}{*}{ Total } & FT & 35 & 35 & - & 0.00 \\
\hline & & NT & 12 & 12 & - & 0.00 \\
\hline & & Total & 47 & 47 & - & 0.00 \\
\hline \multirow[t]{9}{*}{ NP } & \multirow[t]{3}{*}{ Child } & FT & 43 & 42 & 1 & 2.33 \\
\hline & & NT & 65 & 57 & 8 & 12.31 \\
\hline & & Total & 108 & 99 & 9 & 8.33 \\
\hline & \multirow[t]{3}{*}{ Adult } & FT & 22 & 21 & 1 & 4.55 \\
\hline & & NT & 41 & 40 & 1 & 2.44 \\
\hline & & Total & 63 & 61 & 2 & 3.17 \\
\hline & \multirow[t]{3}{*}{ Total } & FT & 65 & 63 & 2 & 3.08 \\
\hline & & NT & 106 & 97 & 9 & 8.49 \\
\hline & & Total & 171 & 160 & 11 & 6.43 \\
\hline \multirow[t]{9}{*}{ Total } & \multirow[t]{3}{*}{ Child } & FT & 68 & 67 & 1 & 1.47 \\
\hline & & NT & 75 & 67 & 8 & 10.67 \\
\hline & & Total & 143 & 134 & 9 & 6.29 \\
\hline & \multirow[t]{3}{*}{ Adult } & FT & 32 & 31 & 1 & 3.13 \\
\hline & & NT & 43 & 42 & 1 & 2.33 \\
\hline & & Total & 75 & 73 & 2 & 2.67 \\
\hline & \multirow[t]{3}{*}{ Total } & FT & 100 & 98 & 2 & 2.00 \\
\hline & & NT & 118 & 109 & 9 & 7.63 \\
\hline & & Total & 218 & 207 & 11 & 5.05 \\
\hline
\end{tabular}

Risk of Infection in Leprosy 
among contacts with long duration or with the same type of infector with reference to treatment status, even though the reductions are very large.

A restricted sample of those with duration of contact more than 8 years give the results shown in Table 5 .

The analysis of variance of the arcsin transformation of $\% \mathrm{I}$ is given in Table 6 .

TABLE 6

Analysis of variance of $\%$ I (Arcsin transformation)

\begin{tabular}{lcrr}
\hline \multicolumn{1}{c}{ Source } & d.f. & $S S(M S)$ & \multicolumn{1}{c}{$F$} \\
\hline Total & 7 & 28569.78 & \\
Main Effects: & & & \\
$\quad$ Prophylaxis (P) & 1 & 18495.54 & 22.53 \\
$\quad$ Age at Start (A) & 1 & 1087.75 & 1.32 \\
$\quad$ Treatment Status (T) & 1 & 485.35 & 0.59 \\
Interactions: & & & \\
$\quad \mathrm{P} \times \mathrm{A}$ & 1 & 1900.68 & 2.32 \\
$\mathrm{P} \times \mathrm{T}$ & 1 & 2473.57 & 3.01 \\
$\mathrm{~A} \times \mathrm{T}$ & 1 & 1016.08 & 1.24 \\
$\mathrm{P} \times \mathrm{A} \times \mathrm{T}$ & 1 & 3110.80 & 3.79 \\
\hline
\end{tabular}

The effect of prophylaxis is highly significant with $\mathrm{P} .001$. It must, however, be noted that the sample size for the sub-divisions of the adequate prophylaxis group is very small and that the interactions $\mathrm{P} \times \mathrm{T}$ and $\mathrm{P} \times \mathrm{A} \times \mathrm{T}$ approach the conventional level of significance of $5 \%$. Also, both the factors, age at start and treatment status have differing distributions in the 2 prophylactic groups.
The 47 cases with adequate prophylaxis had an average duration of 12.3 years (all except one with a duration of 23 years had duration between 9 and 16 years), of which the first 6.4 years on the average was spent without prophylaxis and in the remaining period of 5.9 years (or 71 months) had on the average 57.7 months of prophylaxis, that is, about 10 months per year.

Chemoprophylaxis with DDS does appear to have some real effect on the risk of infection. However, the small samples with adequate prophylaxis render it difficult to disentangle this effect from the effects of duration of contact and treatment status of infector. A fully convincing case could be made only by comparing 2 groups of contacts who have been followed up from birth for a sufficiently long period.

\section{SUMMARY}

An analysis of 575 contacts, with at least 2 examinations separated by a year, has shown a significant reduction in the risk of infection where there is adequate prophylaxis. This effect seems to be real but the small samples with adequate prophylaxis render it difficult to disentangle this effect completely from the effects of duration of contact and treatment status of infector. 